\title{
Thermal Numerical Analysis of the Primary Composite Structure of a CubeSat
}

\author{
Saul Piedra ${ }^{1, *, \dagger}$, Mauricio Torres ${ }^{1, \dagger}$ and Saul Ledesma ${ }^{2, \dagger}$ \\ 1 National Council of Science and Technology (CONACYT)-National Center for Aeronautics \\ Technologies-Center for Engineering and Industrial Development (CENTA-CIDESI), \\ Colón, Querétaro 76270, Mexico \\ 2 National Center for Aeronautics Technologies (CENTA), Colón, Querétaro 76270, Mexico \\ * Correspondence: saul.piedra@cidesi.edu.mx \\ $\dagger$ These authors contributed equally to this work.
}

Received: 7 June 2019; Accepted: 26 August 2019; Published: 4 September 2019

check for updates

\begin{abstract}
A thermal computational analysis for the composite structure of a CubeSat is presented. The main purpose of this investigation is to study the thermal performance of carbon fibre/epoxy resin composite materials with Zinc Oxide nanoparticles in order to be used in the panels of the primary structure of a CubeSat. The radiative heat fluxes over each composite panel are computed according to the orbit trajectory and they are utilized as boundary conditions for the analysis. The direct solar, albedo and Earth infrared radiation fluxes are considered in this study. The model implementation, including the computation of the orthotropic thermal conductivity of the composite material is presented. The thermal simulations were performed for three different orbit inclination angles: the selected mission $\left(\beta=57^{\circ}\right)$, the worst hot $\left(\beta=90^{\circ}\right)$ and the worst cold $\left(\beta=0^{\circ}\right)$. The temperature ranges in the electronic boards are analyzed in order to show that are into the operating limits of each electronic component.
\end{abstract}

Keywords: CubeSat; composite structure; thermal analysis

\section{Introduction}

A single unit (U) CubeSat is a satellite with $10 \times 10 \times 10 \mathrm{~cm}$ dimensions and mass up to $1.33 \mathrm{~kg}$. These space platforms have two main advantages, lower cost, time of design and manufacturing development compared with the traditional systems [1]. Nevertheless, weight restrictions are one of the most critical issues during the design process of a CubeSat. Traditionally, CubeSats have been manufactured using aluminum alloys, the inherent reduction in weight utilizing composites offers an increasing on the payload. However, if any new material is intended to be used in space applications, it must be evaluated in order to validate its thermal and mechanical performance in the environmental and operating conditions to which it will be exposed in space [2]. Several efforts have been developed in order to design composite materials for the structure of a nanosatellite [3-5].

Some other efforts to develop nanosatellites using composite materials include the 3D printed polymer based CubeSats in which additive manufacturing technologies are utilized in order to have rapid prototyping and embed part of the electronics into the 3D printed structure during the manufacturing process [6,7]. A successful implementation of composites into a secondary CubeSat structure was developed in the SwissCube project [8], which is the first satellite entirely built in Switzerland. The Swiss CubeSat was manufactured using an Al alloy frame with glass-epoxy composite panels cured by autoclave. Main mechanical loads are supported by the Al frame and composite panels are used as a secondary structure. Thermal loads are restricted in the glass-fiber panels due to 
the presence of solar cells bonded at their top surface. The SwissCube was launched in 2013 and still continues orbiting the Earth.

Currently, the incorporation of nanoparticles as polymer reinforcement has shown huge potential for providing enhancement performances for different applications at very low filler content (lower than $1 \mathrm{wt} \%)[9,10]$. In recent works, they allow an increase of the Glass transition temperature $(\mathrm{Tg})$ of polymers and/or a shift of their continuous working temperature towards higher values [11]. Composite materials added with different kind of nanoparticles can be turn into a solution to implement composites for aerospace applications, specially, when the environmental conditions require high performance behavior from the thermal, mechanical or UV resistant points of view.

The CubeSat design development requires predicting the temperature ranges of the CubeSat structure at the space environmental conditions in order to evaluate whether or not the electronic devices and payload remain into their operational and safety limits [1]. In Reference [12], the authors presented a thermal analysis for the STEP Cube Lab (Cube Laboratory for Space Technology Experimental Projects), a CubeSat framework for educational purposes. The analysis were performed using SINDA/FLUINT Thermal Desktop tool. The radiation fluxes and exchange factors were computed using RadCAD [13]. The temperature behavior as function of time is reported for the external panels and the main internal components of the CubeSat, showing that all the electronic systems satisfy the temperature requirements.

A thermal analysis for a $3 \mathrm{U}$ CubeSat was carried out in Reference [14]. Based on the orbit mechanics results, the authors computed the direct solar and albedo radiative heat fluxes as function of the CubeSat position along its orbit. The transient thermal model was implemented in ANSYS 13 software and, minimum and maximum temperatures reached by the CubeSat are presented considering only the aluminum structure and a multi-layer insulation throughout the aluminum structure. A similar but more complete analysis was done by Reference [15] for the TRIO-CINEMA (Triplet Ionospheric Observatory - CubeSat for Ion, Neutral, Electron, MAgnetic fields). The authors took into account the optical properties of the main components of the CubeSat to compute the radiation heat fluxes. Using the computational results, a passive thermal control was design in order to comply the temperature requirements for each electronic device. For the case of composite structures, in Reference [3], the authors compared the thermal performance of aluminum and composite materials for satellite structures. They also presented the possibility to use composite materials with thermal conductivity larger than the aluminum. As the authors commented, this can help to remove the excess of heat from the electronic devices reducing the thermal control cost. Their results showed that the use of this high conductivity composite materials can significantly decrease the temperature gradients along the satellite structure.

In the scope of the AEM-CONACYT (Mexican Aerospace Agency) project entitled, "Design and characterization of composite materials for CubeSat structure", the research objectives are the following: (1) To investigate a family of low-cost composite materials that can handle space environments and (2) To evaluate the mechanical-thermal and radiation performance of the down-selected composite materials in a CubeSat prototype. At this point, it is important to comment that actual space composite systems are based in cyanate-ester resins. Cyanate-ester resins have as their main advantage a high glass transition temperature $\left(\mathrm{Tg}=400{ }^{\circ} \mathrm{C}\right)$, low dielectric constant, thermal stability and low flammability, which makes it an excellent candidate for electronic and spatial applications [16]. Nonetheless, the cost of cyanate-ester resin is more than 6 times (2000 USD/gal) [17] compared with a low flammable FAR 25 [18] certified epoxy resin (300 USD/gal) [19]. Recent studies have compared both systems in terms of flame retardancy and thermal properties [20,21]. Conclusions have established that epoxy systems added with fire retardant and/or ceramic nanofillers improve their thermal behavior and can be considered as a candidate for spatial applications [22]. Having in mind those references, an epoxy resin was selected considering the following aspects: (1) mechanical and thermal properties, (2) compatibility with carbon fibres and (3) cost-benefit. 
At the actual stage of the project, the family of promising composite materials has been developed and tested at coupon level. The purpose of this study is to communicate the thermal performance of the down-selected composite material considering the CubeSat structure in a possible space environment.

In the present work, a thermal analysis is implemented to evaluate the performance of the proposed CubeSat composite structure. The design configuration of our CubeSat employs the composite panels as main structure, because no $\mathrm{Al}$ main frame is considered. A Carbon fibre/Epoxy resin composite with Zinc Oxide nanoparticles was used for the CubeSat panels. Additionally, we propose this Out-of-Autoclave (OoA) manufacturing process, such as Resin Transfer Molding (RTM), due to the novelty trends respecting environmental agreements such as Horizon 2020 and Europe Horizon [23]. The principal reason for using a composite material is the reduction of weight with respect to the classic aluminum structure used in most of the CubeSats that are currently operating. During the first stage of the project it was found that the addition of nanoparticles increase the resistance to UV radiation with respect to the original composite material [24], this effect has been found for different composite and coatings materials $[25,26]$. Also, the characterization of this composite demonstrated that the presence of the Zinc Oxide nanoparticles $(\mathrm{ZnO})$ into the polymeric matrix slightly improve its thermal properties [27].

\section{Materials and Methods}

\subsection{Conceptual Design}

The proposed primary CubeSat structure consists in six quasi-isotropic composite panels as shown in Figure 1a. The conceptual model of the structure is simplified with respect to a final design of a CubeSat. However, at this stage of the design process, only the evaluation of the composite material with nanoparticles was performed under the severe thermal conditions along a Low-Earth-Orbit. With this in mind, all the other external components such as solar cells are not considered in this study. The main objective is to demonstrate that the composite panels can provide proper thermal operating conditions for the electronic devices during the satellite mission. In Figure 1a, the panels nomenclature with respect to the coordinate reference frame is shown. The internal electronic devices configuration of the satellite is presented in Figure 1b. Only the relevant electronic devices from the thermal point of view were taken into account for the analysis (Electric Power Supply EPS, GPS, communication boards and battery pack, see Table 1).

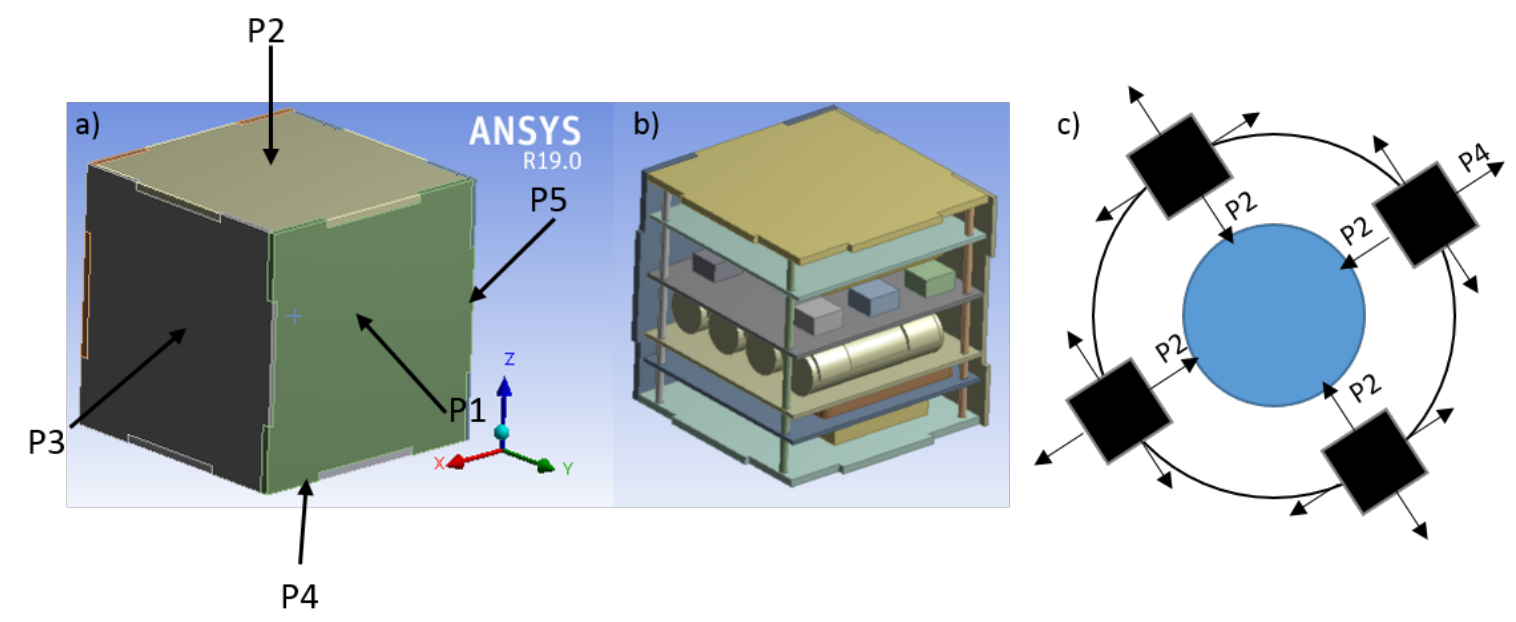

Figure 1. Conceptual design of the CubeSat primary structure, (a) external composite panels (b) internal electronic devices arrangement and (c) panels configuration and Nadir-pointing scenario scheme. 
Table 1. Operating temperature limits for the main on-board systems [12].

\begin{tabular}{lccc}
\hline \multicolumn{1}{c}{ Unit } & Power Dissipation (W) & Operating Temperature Range $\left({ }^{\circ} \mathbf{C}\right)$ \\
\hline EPS board & 0.1 & -40 & 85 \\
Battery pack & 0.6 & -20 & 60 \\
GPS board & 0.27 & -40 & 85 \\
Communication board & 0.27 & -30 & 60 \\
\hline
\end{tabular}

The thermal conditions to which the structure of the satellite will be exposed are strongly dependent on the orbital parameters. Then, a specific mission was defined to estimate these orbital parameters and consequently the time-dependent radiative heat fluxes over the composite panels of the CubeSat. An orbit inclination angle $\beta=57^{\circ}$ and an altitude of $250 \mathrm{~km}$ (Low-Earth-Orbit) were used as input parameters. From this information and assuming a circular orbit, the period, angular radius, sunlight and eclipse stages were determined.

A nadir-pointing scenario was selected (see Figure 1c) to evaluate the thermal performance of the composite panels. Nadir-pointing is a case in which the same face of the CubeSat is always pointing to the centre of the Earth. This scenario allows for the four faces exposed to direct solar heat flux to exhibit a sinusoidal behavior of radiation [28]. The proposed composite material for the primary structure panels is a quasi-isotropic $\left[0 / 45_{2} / \overline{0}_{3}\right]_{S}$ carbon fibre/epoxy resin laminate with $3 \mathrm{~mm}$ in thickness. Resin Transfer Molding (RTM) process was implemented to manufacture them. Before the RTM process, the epoxy resin was added with $0.25 \mathrm{wt} \%$ of Zinc Oxide nanoparticles. The Zinc Oxide nanoparticles decreased the degradation of the material when it is subjected to UV radiation. However, this effect is outside of the scope of the present investigation and is therefore not quantified. In order to characterize the thermal properties of the composite material, thermogravimetric (TGA) and transient thermal response analysis were performed and the thermal conductivity, diffusivity and heat capacity were calculated [27]. In Table 2, the thermal properties of the epoxy resin/ZnO nanoparticles and the carbon fibre are shown, the properties of the carbon fibre were taken from Reference [29].

Table 2. Thermal properties of the materials $[19,27]$.

\begin{tabular}{lccc}
\hline \multicolumn{1}{c}{ Material } & Thermal Conductivity $(\mathrm{W} / \mathbf{m ~ K )}$ & Heat Capacity $(\mathbf{J} / \mathbf{k g ~ K})$ & Density $\left(\mathbf{k g} / \mathbf{m}^{\mathbf{3}}\right)$ \\
\hline Epolam 2500/ZnO 0.25 wt \% & 0.4 & 1890 & 1210 \\
Epolam 2500 & 0.35 & 1760 & 1210 \\
AS4 Carbon Fibre & 6.83 & 1130 & 1790 \\
Al 5052-H32 & 138 & 880 & 2680 \\
\hline
\end{tabular}

The appropriate thermal design of the CubeSat can allow to maintain the on-board equipment within their operating temperature limits. These operating limits are shown in Table 1 for the most relevant electronic devices. As it was commented, the motivation to change from the classical aluminum to a composite primary structure is the weight reduction that can be achieved. In this sense, the weight of the proposed composite structure is $226 \mathrm{~g}$. A comparable structure with solid-walls configuration and manufactured in $\mathrm{Al} 5052-\mathrm{H} 32$ sheet with a thickness of $0.080^{\prime}$ ( $2.032 \mathrm{~mm}$ ) weighs around $324 \mathrm{~g}$. This means that using the composite panels, a 30 percent reduction of the weight of the CubeSat structure can be obtained.

\subsection{Heat Radiation Sources}

The environmental conditions to which the CubeSat is exposed are mainly dictated by the orbital parameters and the external radiation sources as the direct solar $\left(q_{s}\right)$, albedo $\left(q_{a}\right)$ and Earth infrared $\left(q_{i}\right)$ radiation. It is important to consider the specific translation and rotation motion of the CubeSat along its orbit, since this effect causes that the satellite receives heat on one side and dissipate heat through the remaining side, promoting a temperature gradient between the panels of the CubeSat. 
The computation of the radiative heat fluxes is the most critical issue in the thermal analysis for a nanosatellite. The direct solar radiation depends on the solar constant $\left(C_{s}\right)$ defined as the intensity of sunlight radiation perpendicular to a surface at the mean distance from Earth to the Sun. For this analysis an average solar constant equal to $1367 \mathrm{~W} / \mathrm{m}^{2}$ was used, since a circular orbit assumption for the CubeSat was established. Due to the cubic shape of the nanosatellite, there is no coupling between faces, it means that the rays reflected by one face of the CubeSat never falls upon other. The direct solar flux is computed as the projection of the solar vector to the corresponding face normal:

$$
q_{s}=C_{s} \cos \gamma_{i}
$$

where $\gamma_{i}$ is the angle between solar vector and the normal vector to the $i$ CubeSat face. The albedo radiation flux is quite more difficult to compute, since it depends on many parameters. Some guidelines for the selection of the parameters used to compute albedo heat flux can be found in Reference [30]. Following a simple formulation presented in Reference [31], the albedo flux can be computed as function of the albedo reflectivity coefficient $(a)$, the sun-earth-satellite angle $(\theta)$ and the so-called view factor $\left(F_{E}\right)$ as:

$$
q_{a}=C_{s} a(\cos 0.9 \theta)^{e} F_{E}
$$

The view factor of each face can be easily estimated as:

$$
F_{E}=r^{2 \cdot 1}(\sin \rho / 2)^{e}
$$

where $r=R /(R+h)$, being $R$ the Earth radius and $h$ the mission altitude and the exponent $e$ is computed as function of $r$ through a polynomial expression that can be found in Reference [31]. This formulation is an alternative approach to the chart presented in Reference [32] for the albedo heat flux and the view factor.

For the Earth infrared heat flux an average value $E B B=240 \mathrm{~W} / \mathrm{m}^{2}$ can be used multiplied by the corresponding view factor of the $i$ face.

Additionally to the external radiative heat fluxes, the face radiation to the space must be calculated. The standard environmental conditions used for a spacecraft thermal analysis considers a temperature of $5 \mathrm{~K}$. The CubeSat will radiates energy to the space and it can be computed through the Stephan-Boltzmann radiation law. Finally, the internal power generation from the electronic devices is modelled as a volumetric heat source in each one of the electronic boards of the CubeSat. In Table 1, the heat dissipation from the most relevant electronic devices is listed.

A python script was developed in order to compute the orbital parameters and radiative heat fluxes as function of the mission definition. In Figure 2, the total radiative heat fluxes $\left(q=q_{s}+q_{a}+q_{i}\right)$ on each CubeSat panel are shown for one complete orbit. As can be observed, the fluxes exhibit almost a sinusoidal behavior. It is also illustrated the eclipse period of the nanosatellite orbit. Due to the inclination angle, the panel 6 (P6) receives the largest amount of direct solar radiation and the nadir (P2) the largest amount of albedo and Earth infrared radiation. The large difference between the incident energy over each composite panel will produce temperature gradients that can affect the integrity of the electronic devices and compromise the correct operation of the electronic boards. From the solution of the heat transfer model it can be determined if the composite material with nanoparticles will be able to maintain the temperature range into the safety conditions of the electronic systems in the CubeSat. 


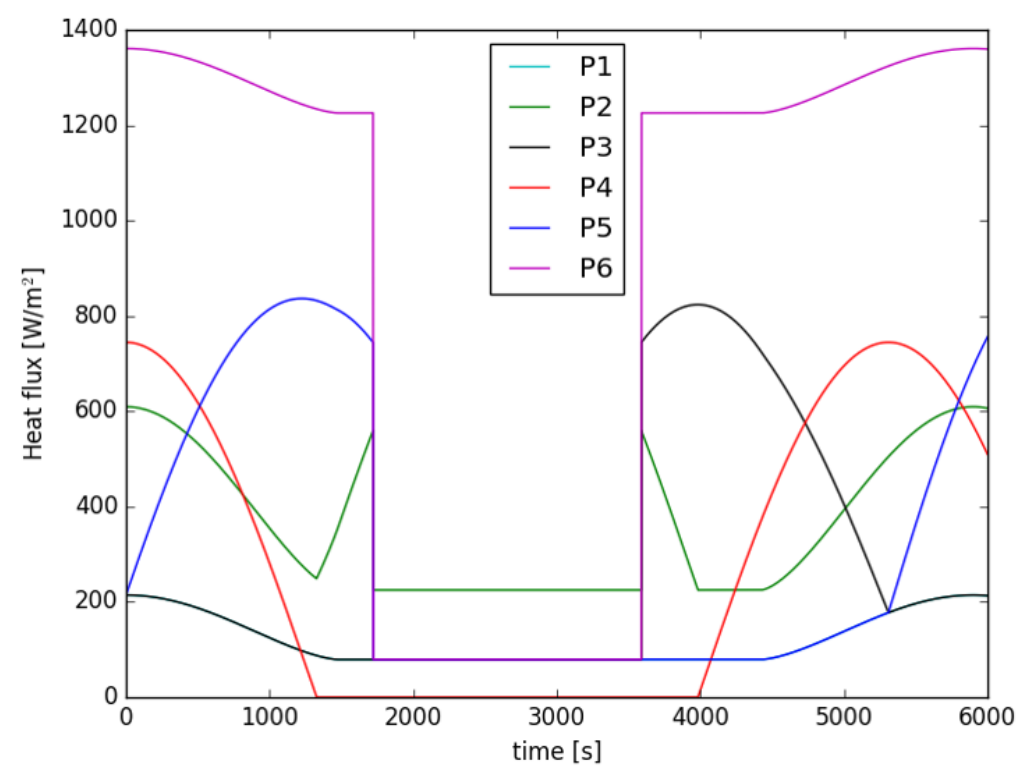

Figure 2. Radiative heat fluxes over each CubeSat panel as function of time along one orbit $\left(\beta=57^{\circ}\right)$.

\subsection{Model Implementation}

A time dependent heat transfer model was implemented in ANSYS 19 [33]. The mathematical model is based on the energy conservation equation [1]:

$$
\frac{\partial T}{\partial t}=\alpha \nabla^{2} T+\frac{\dot{q}}{\rho c_{p}}
$$

where $\alpha=k / \rho c_{p}$ is the thermal diffusivity, $k$ is the thermal conductivity, $\rho$ is the density, $c_{p}$ is the heat capacity of the material and $\dot{q}$ is the heat dissipation from the internal electronic devices. Due to the orthotropic nature of the composite materials, the thermal conductivity must be evaluated in each direction. The orthotropic thermal conductivity must be referenced by a local coordinate system $\left(x^{\prime}, y^{\prime}, z^{\prime}\right)$ on each face of the CubeSat at which the $z^{\prime}$-axis is always on the thickness direction of the composite panel. For the in-plane thermal conductivity $\left(k_{x^{\prime}, y^{\prime}}\right)$ and the heat capacity, the simple rule of mixtures was used:

$$
k_{x^{\prime}, y^{\prime}}=k_{f} V_{f}+k_{m}\left(1-V_{f}\right)
$$

where $k_{f}$ and $k_{m}$ are the thermal conductivities of the carbon fibre and epoxy matrix with $\mathrm{ZnO}$ nanoparticles, respectively, and $V_{f}$ is the fibre volume fraction. For the computation of the thermal conductivity in the thickness direction of the composite laminate $\left(k_{z^{\prime}}\right)$, the Clayton model was used [34]:

$$
k_{z^{\prime}}=\frac{K_{m}}{4}\left[\sqrt{\left(1-V_{f}\right)^{2}\left(\frac{K_{f}}{K_{m}}-1\right)^{2}+\frac{4 K_{f}}{K_{m}}}-\left(1-V_{f}\right)\left(\frac{K_{f}}{K_{m}}-1\right)\right]^{2}
$$

The surface to surface radiation in the interior of the CubeSat was also modeled using the S2S model implemented in ANSYS 19. This model allows to simulate thermal radiation exchange between surfaces forming an enclosure. The medium that fills the space between the surfaces is non-participating, it means that the medium inside the CubeSat does not emit, absorb or scatter radiative energy. Therefore, the amount of radiation received and emitted by each surface is only defined by their optical properties. The radiation model S2S from ANSYS assumes the surfaces to be gray and diffuse, then, the emissivity $(\epsilon)$ is equal to the absorptivity $(\alpha)$. In the computational simulations the emissivity for the composite panels was taken as 0.81 [35] and for the PCBs (FR4) equal to $0.6[15]$. 
A hexahedral mesh was built to discretize the CubeSat structure including the composite panels and the internal electronic boards. The electronic boards were model using the FR4 material properties as in Reference [12]. In Figure 3 a total mesh with 52,400 elements is shown. For the composite panels a mesh with 10 elements along the thickness was used in order to capture the effect due to the orthotropic conductivity of the composite material. The total radiative heat fluxes were applied as boundary conditions on each composite panel (see Figure 3). The solution of the model was done for five orbits in order to minimize the initial conditions effect and compute the periodic behavior of the temperature along the orbit of the CubeSat.

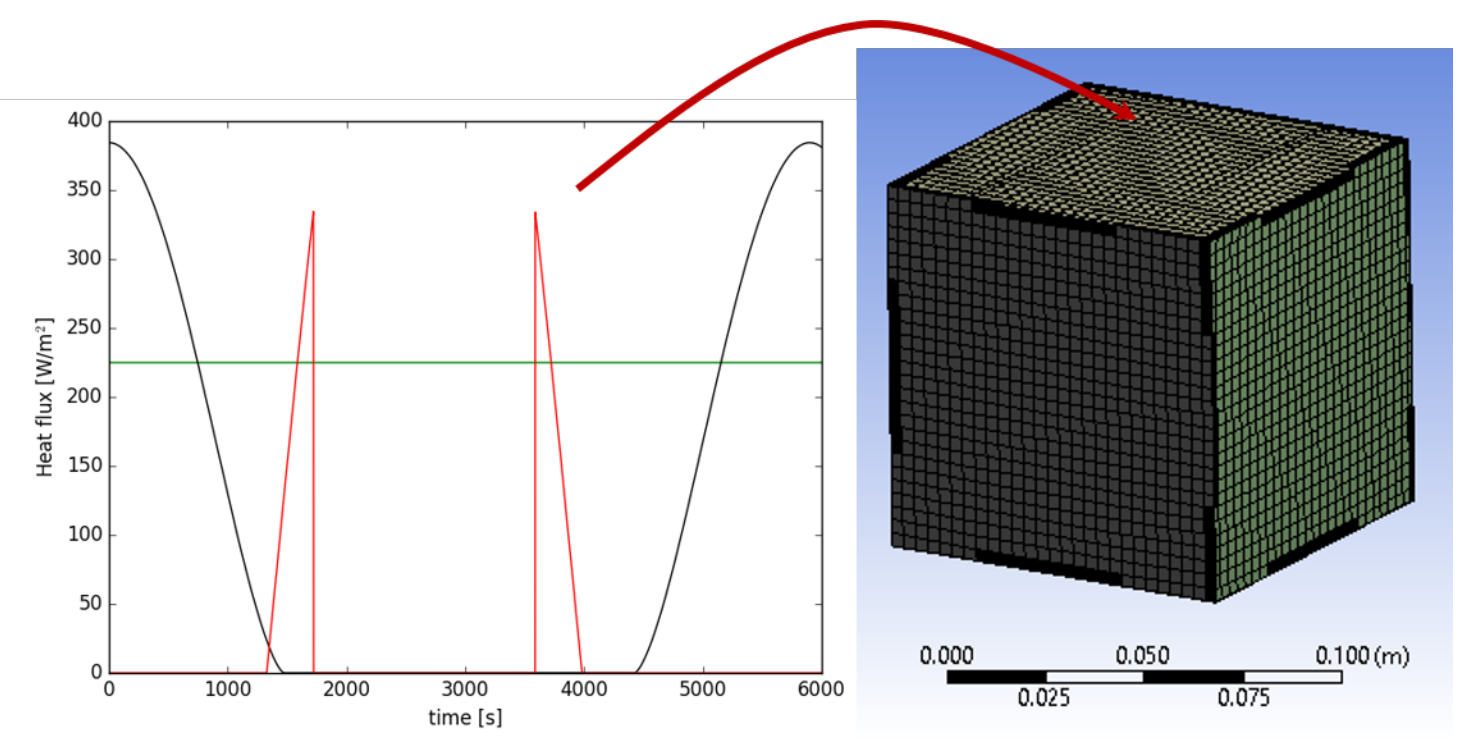

Figure 3. Computational mesh and radiative heat fluxes over panel 2 as function of time, black, red and green curves correspond to the direct solar, albedo and Earth infrared radiative heat fluxes over P2 $\left(\beta=57^{\circ}\right)$.

\section{Results and Discussion}

The average temperature as function of time was computed for each panel. The simulations were performed for the defined mission with an inclination angle of $57^{\circ}$. Additionally, in order to show the feasibility for using this composite material for any orbital parameters, the radiation fluxes were computed for the worst cold and hot cases $\left(\beta=0,90^{\circ}\right)$ and the thermal analysis were also carried out for these both conditions. In Figure 4 , the temperature field in each panel for the case of $\beta=57^{\circ}$ at $t=19,620 \mathrm{~s}$ (the coldest instant of time during eclipse period of the orbit) is shown. As can be observed, the panel 5 is the coldest one, since no albedo and Earth infrared radiation fluxes fall on this panel along the orbit. The temperature fields on the CubeSat composite panels is shown in Figure 5 for an instant of time during the sunlight period of the orbit. Due to the inclination angle of the orbit, the maximum temperature appears in P6, while in P1 and P3 the temperature falls below $263 \mathrm{~K}\left(-10^{\circ} \mathrm{C}\right)$. At this point, it is important to discuss the results in terms of the temperatures ranges at which the electronic devices into the CubeSat can operate (Table 1). The average temperature in each panel as function of time is plotted in Figure 6 during five complete orbits. The minimum and maximum temperatures occurs periodically at the eclipse and sunlight stages of the orbit. The results show that the average temperature in each panel never falls below the lower limit of operation of the CubeSat electronic systems. Due to the selected orbit, P1 is the coldest one, since this panel is not exposed to the direct solar radiation along the whole orbit. On the other hand, panel P6 is the hottest reaching a temperature upon $340 \mathrm{~K}\left(67^{\circ} \mathrm{C}\right)$. 


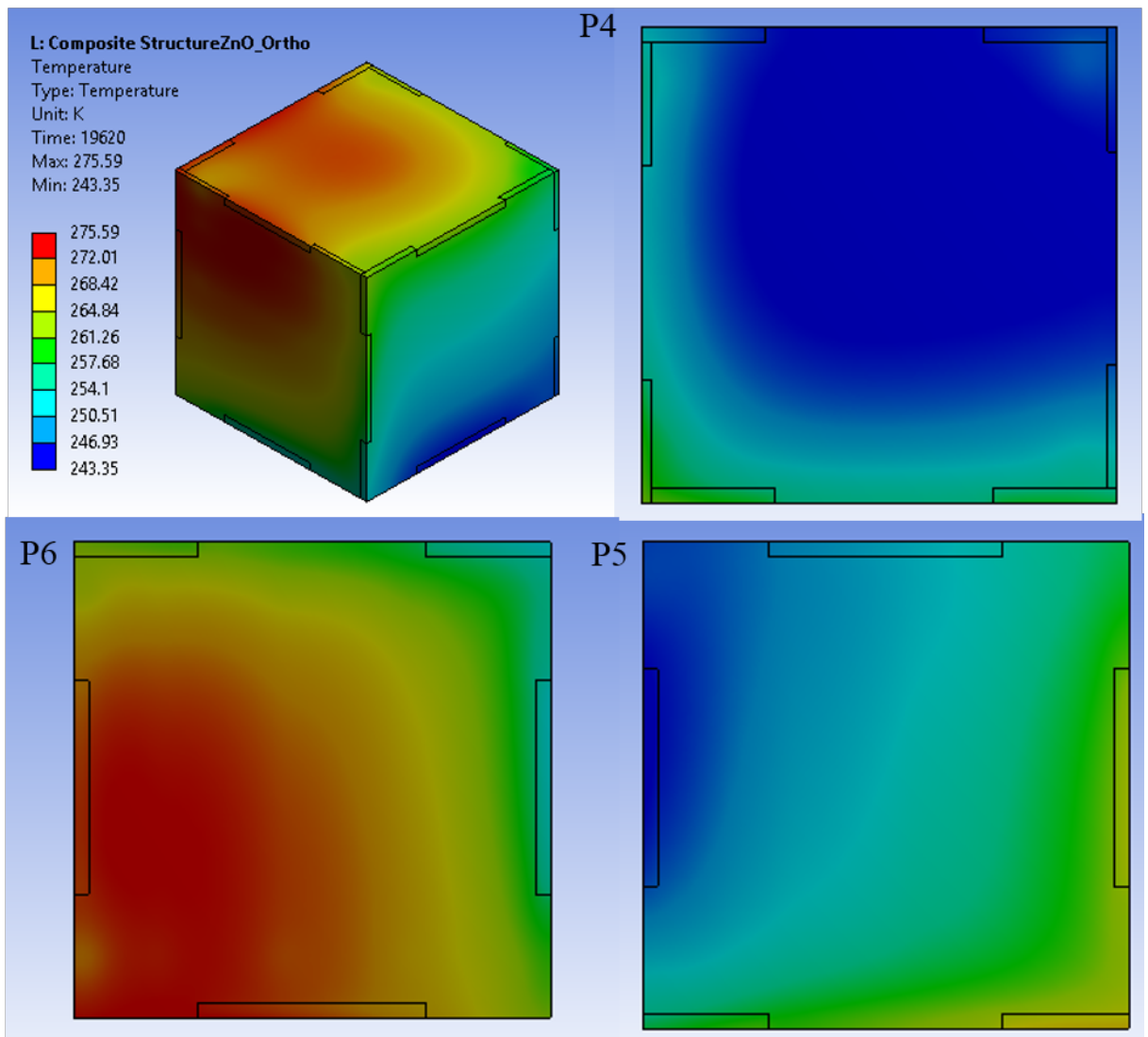

Figure 4. Temperature field on the surface of the CubeSat panels at $t=19,620 \mathrm{~s}\left(\beta=57^{\circ}\right)$.
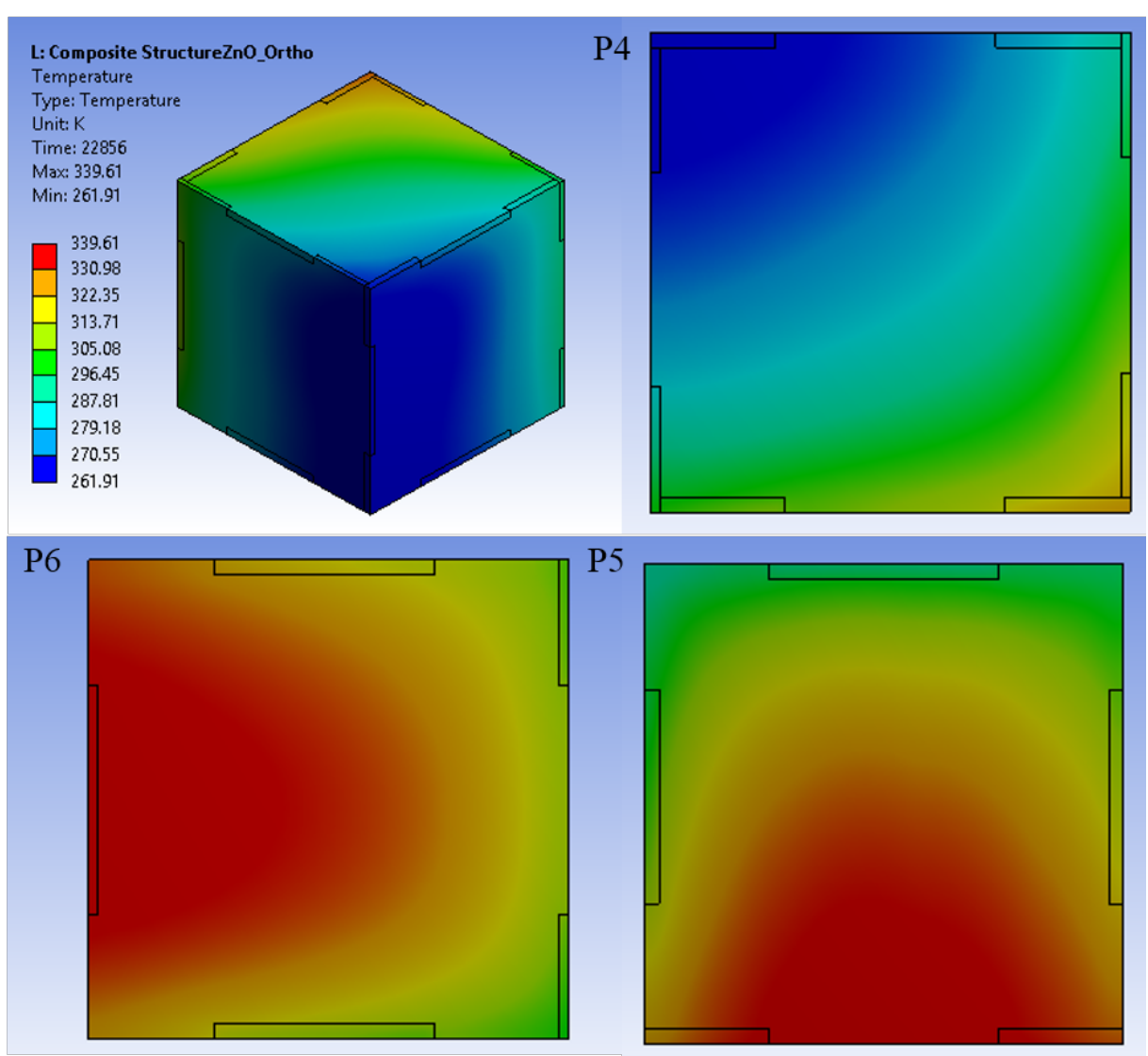

Figure 5. Temperature field on the surface of the CubeSat panels at $t=22,856 \mathrm{~s}\left(\beta=57^{\circ}\right)$. 


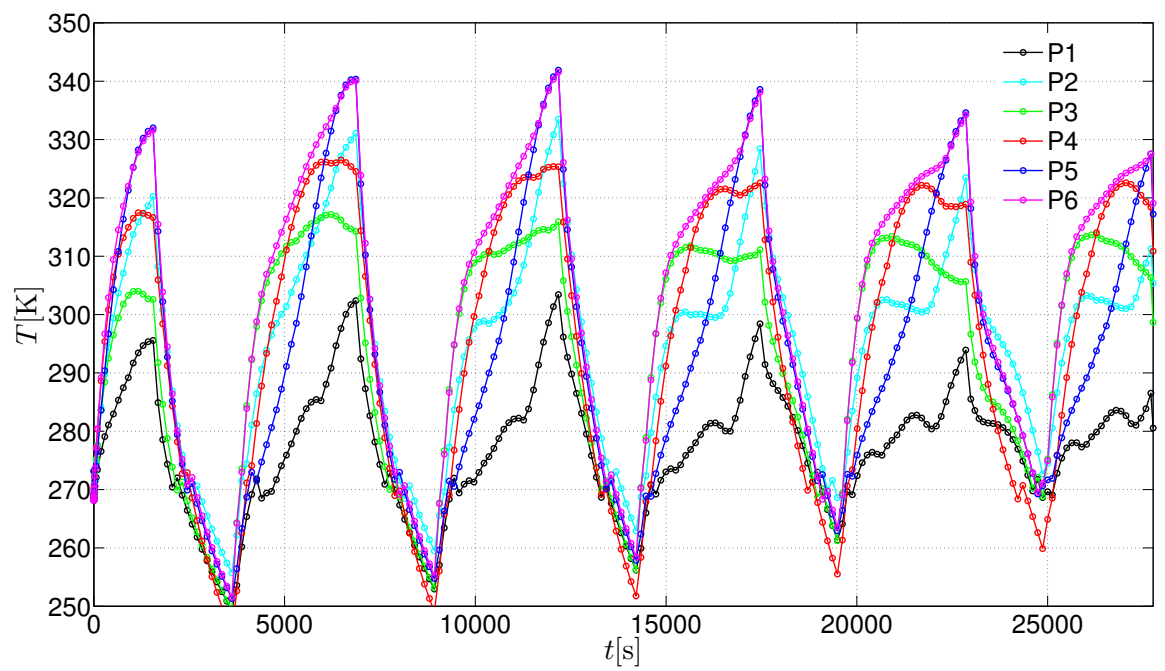

Figure 6. Average temperature in each composite panel as function of time $\left(\beta=57^{\circ}\right)$.

The electronic boards temperature fields at $t=19,620 \mathrm{~s}$ and $t=22,856 \mathrm{~s}$ are shown in Figure 7 . It can be observed that the temperature in each electronic board for the hottest and coldest instants along the orbit, depends mostly on the temperature gradient that appears over the external composite panels. In order to analyze quantitatively the temperature in each electronic board, the average temperature of each one as function of time is plotted in Figure 8. As can be seen, the temperature in the electronic boards follows almost the same behavior as the temperature in the composite panels. The temperature for each one of the electronic boards at any instant of time are into the range of their safety operating limits, showing the feasibility to use the composite panels as the primary structure for a CubeSat that perform the selected mission.

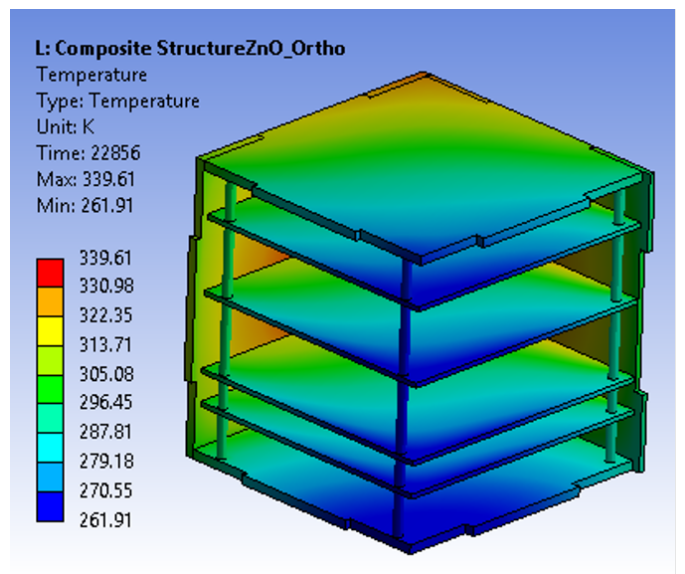

(a)

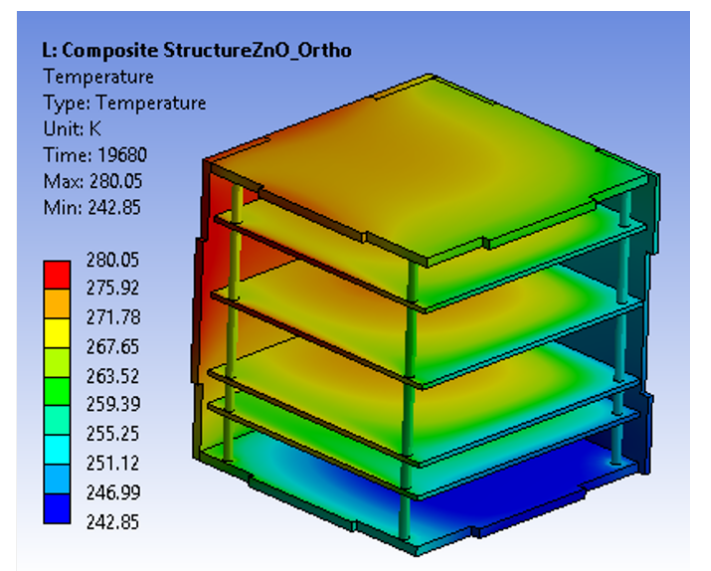

(b)

Figure 7. Temperature field at the surface of the CubeSat panels and electronic boards, (a) $t=19,620 \mathrm{~s}$, (b) $t=22,856 \mathrm{~s}\left(\beta=57^{\circ}\right)$.

To compare the thermal behavior between the composite material and an aluminum structure, the simulation was carried out with the properties of the aluminum 5052-H32 sheet with a thickness of $0.080^{\prime}(2.032 \mathrm{~mm})$ black paint, the thermal properties are listed in Table 2 and the emissivity of this alloy was taken as 0.89 [15]. The average temperature in each panel as function of time is plotted in Figure 9. As can be observed, the instantaneous average temperatures in all the aluminum panels are almost the same and the temperature range is similar to the exhibited in the case of the composite structure. 


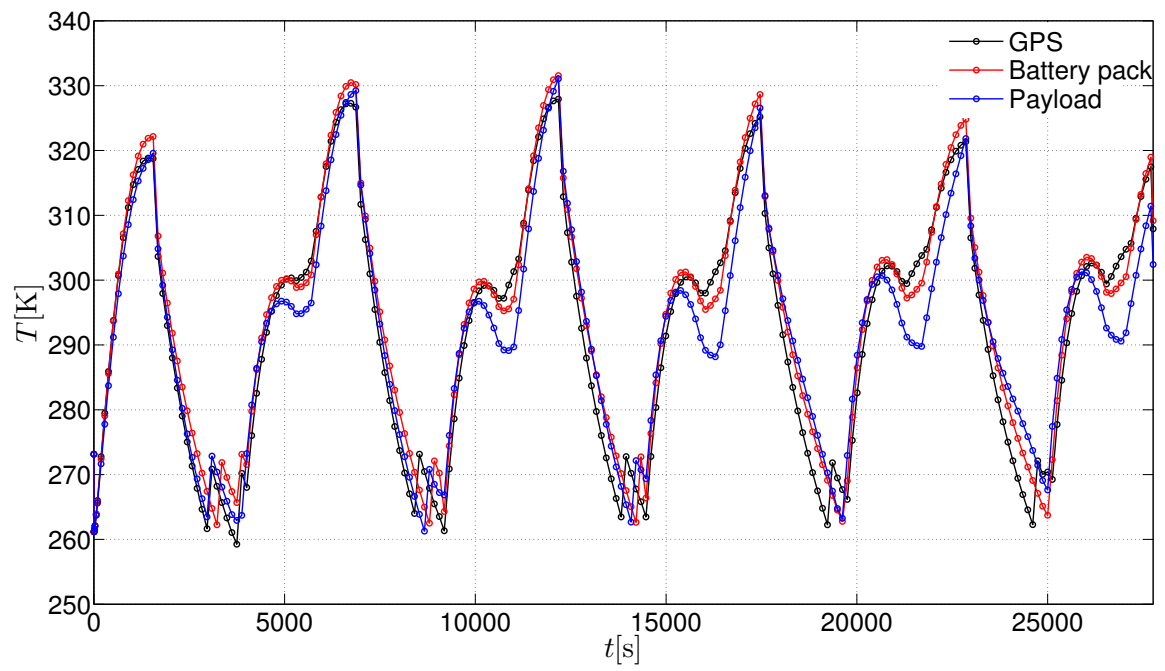

Figure 8. Average temperature in the electronic boards as function of time $\left(\beta=57^{\circ}\right)$.

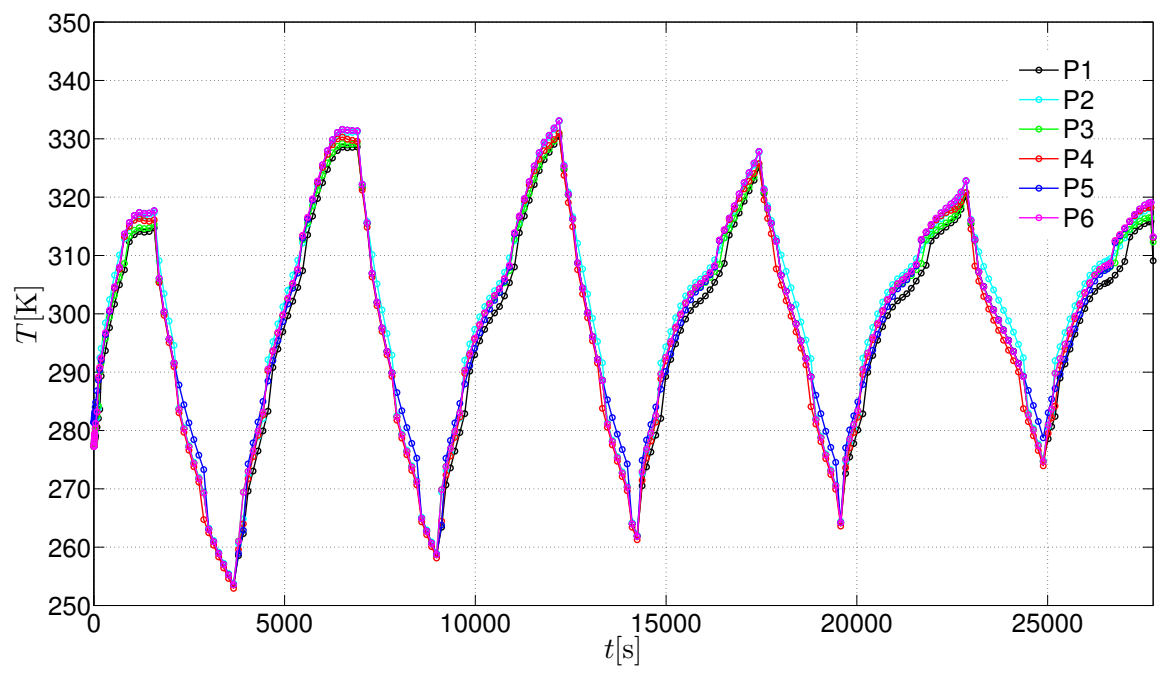

Figure 9. Average temperature in each aluminum panel as function of time $\left(\beta=57^{\circ}\right)$.

It is important to highlight that from the thermal point of view, the aluminum structure is better than the composite one, since its high thermal conductivity allows to reduce the temperature gradients in the CubeSat, however, the composite structure complies with the thermal requirements and the reduction of weight due to the use of a composite material makes it an attractive option for applications where the payload needs to be maximized.

The thermal validation for the conceptual design of the composite structure requires the evaluation of the behavior at the worst hot and cold orbit conditions. The coldest orbit occurs when the CubeSat spends the longest time eclipsed by the Earth $\left(\beta=0^{\circ}\right)$ and the electronic devices operate at the minimum power. The hottest orbit case occurs when the eclipse time is minimized $\left(\beta=90^{\circ}\right)$. For both cases the radiation fluxes were computed and incorporated in the heat transfer model. The average temperatures in each panel as function of time are plotted in Figures 10 and 11 for worst hot and cold orbit cases, respectively. For the worst hot case, the panel 5 receives perpendicularly the direct solar heat flux along the entire orbit reaching temperatures around $350 \mathrm{~K}\left(77^{\circ} \mathrm{C}\right)$, on the other hand, P1 does not receive any radiative heat flux and its minimum temperature is about $263 \mathrm{~K}\left(-10^{\circ} \mathrm{C}\right)$, the large temperature difference between the hottest and coldest composite panels can promote thermo-mechanical stresses due to the thermal expansion of the material that must be studied during 
the structural analysis of the CubeSat. Nonetheless, as a quasi-isotropic configuration was chosen, it can be assumed that their thermal expansion will be the same in the in-plane principal axes of the panels $(0,90, \pm 45)$. For the thermal analysis purposes, the important issue is that the P5 reaches a temperature that is very close to the operating limits of the electronic devices. For the worst cold case (Figure 11), the temperature of the panels present a periodic behavior in a range of temperatures from -245 to $325 \mathrm{~K}$. The minimum temperature in the composite panels for the worst coldest case is lower than the operating limits of batteries $\left(-20^{\circ} \mathrm{C}\right)$ and close to the communication board limit $\left(-30^{\circ} \mathrm{C}\right)$. In order to wrap up the analysis, the average temperature in the electronic boards for the worst hot and cold cases are plotted in Figures 12 and 13. For the worst hot case the temperature range limits for all the electronic boards are satisfied. The average temperature in the electronic boards for the worst cold case has a range about $70 \mathrm{~K}$ during a complete orbit (see Figure 13). The issue in this particular case is that the temperature in the electronic boards falls below $255 \mathrm{~K}\left(-18^{\circ} \mathrm{C}\right)$, compromising the operation of nanosatellite batteries. Then, for an orbit with an inclination angle close to zero, inner heaters will be necessary to ensure the correct behavior of all the CubeSat electronic systems.

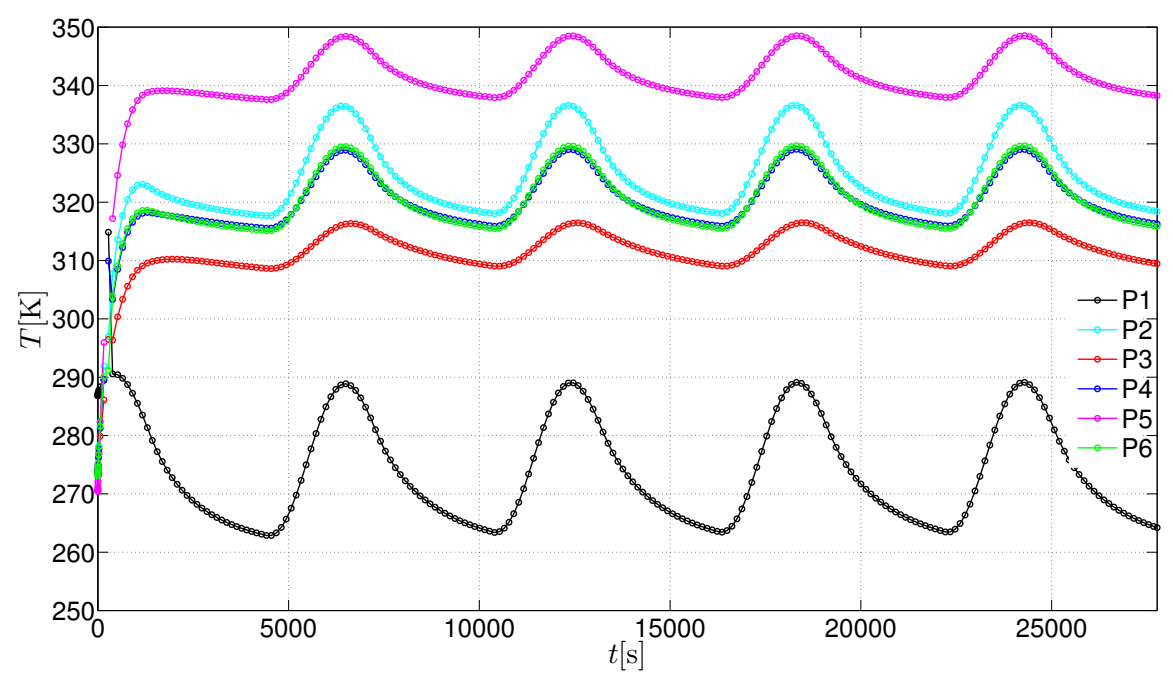

Figure 10. Average temperature in each composite panel as function of time $\left(\beta=90^{\circ}\right)$.

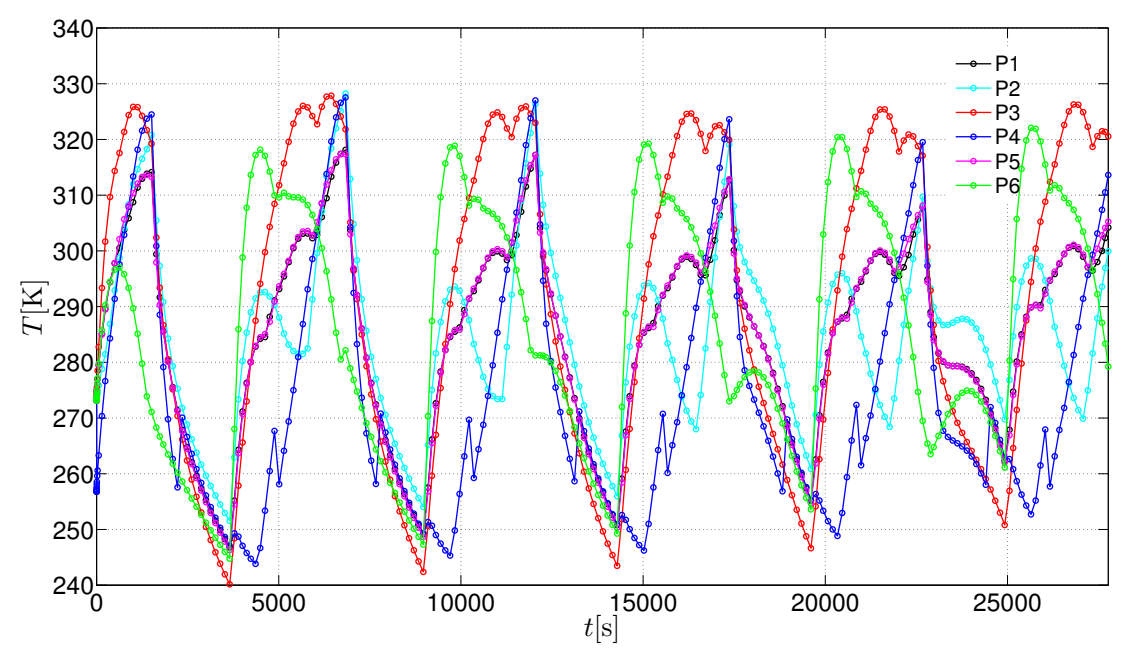

Figure 11. Average temperature in each composite panel as function of time $\left(\beta=90^{\circ}\right)$. 


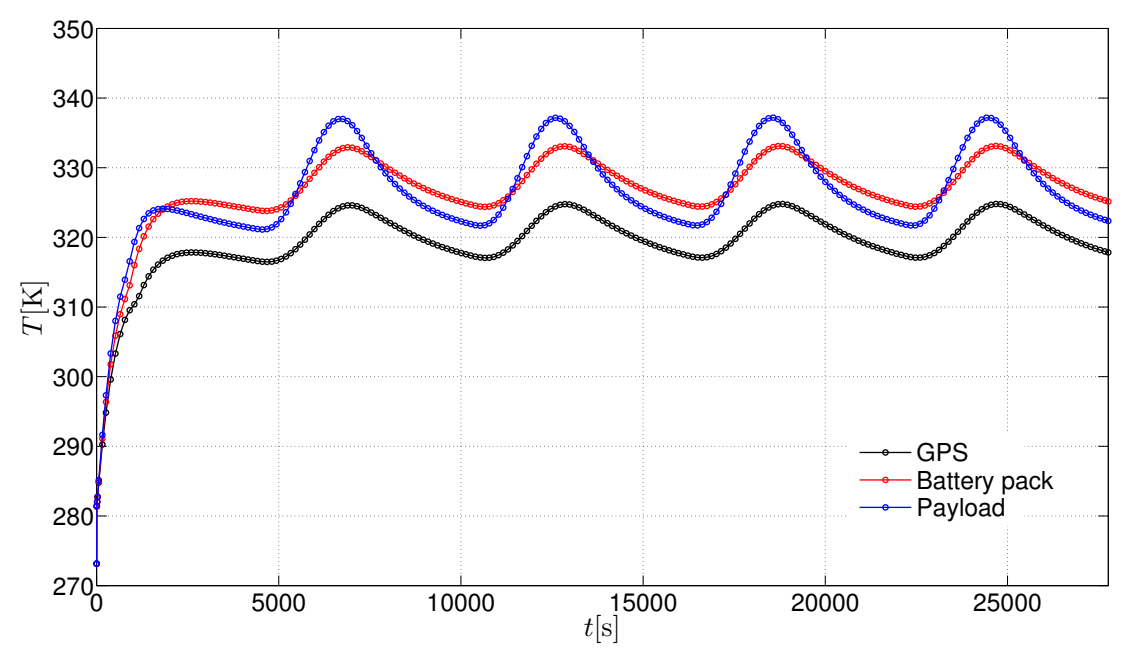

Figure 12. Average temperature in the electronic boards as function of time $\left(\beta=90^{\circ}\right)$.

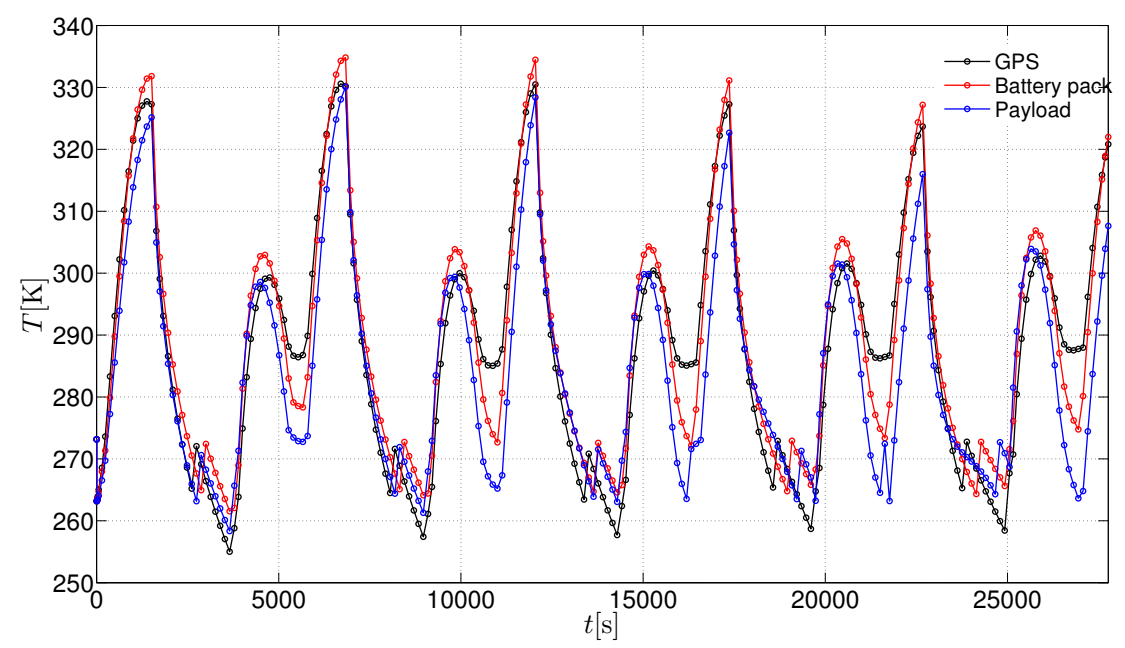

Figure 13. Average temperature in the electronic boards as function of time $\left(\beta=0^{\circ}\right)$.

\section{Conclusions}

The thermal analysis for the primary composite structure of a CubeSat was carried out. The main idea was to demonstrate from the thermal point of view, the feasibility for using a carbon based composite material with $\mathrm{ZnO}$ nanoparticles for the primary structure of a CubeSat. A computational analysis was performed solving the transient energy conservation equation implemented in ANSYS 19. The orthotropic nature of the composite material was included in the solution using Clayton model for the thermal conductivity calculation. The direct solar, albedo and Earth infrared radiative heat fluxes were computed as function of the orbit parameters and the position of each composite panel along the orbit trajectory. For the selected orbit inclination angle $\left(\beta=57^{\circ}\right)$ and the worst hot orbit $\left(\beta=90^{\circ}\right)$, the temperature ranges of the composite panels and the internal boards met with the safety operating limits of the electronic systems. However, for the worst cold orbit $\left(\beta=0^{\circ}\right)$ the minimum temperature reached is very close to the lowest operational limit of the battery pack $\left(-18{ }^{\circ} \mathrm{C}\right)$ and additional thermal control system must be incorporated to the CubeSat design. It is important to note that the hottest temperatures and temperature gradients between the panels reached by the CubeSat are higher than the temperatures for the aluminum structures computed (see Figure 9 and reported in the literature $[1,12,15]$. The main reason is the lower thermal conductivity of the composite material that reduces the heat transfer in the structure of the CubeSat and increases the temperature 
gradients between the panels. Although, with the results presented in this work, it has been verified that the thermal design of the CubeSat structure using the proposed material satisfies the temperature requirement of on-board electronic equipment. In addition to the thermal analysis presented in this work, static and dynamic structural analyzes are required to complement the feasibility study of the use of the proposed composite material for the main structure of a CubeSat. Specifically, it must carry out vibrational analysis to validate the mechanical performance for the material and establish the compliance of the CubeSat Standard [2].

Author Contributions: Conceptualization, S.P. and M.T.; methodology, S.P., M.T., S.L.; software, S.P.; formal analysis, S.P., M.T. and S.L.; investigation, M.T., S.P.; resources, M.T.; writing—original draft preparation, S.P., M.T. and S.L.; writing - review and editing, M.T. and S.P.; visualization, S.P.; project administration, M.T.; funding acquisition, M.T.

Funding: This research was funded by CONACYT through the Research Fund for the Development of Space Activities (FIDAE), grant number 275783.

Acknowledgments: Saul Piedra and Mauricio Torres, convey their special appreciation to the "CONACYT Research Fellow Program (Catedras CONACYT)". All of the authors convey their appreciation to Miguel Vergara for his technical support.

Conflicts of Interest: The authors declare no conflict of interest.

\section{References}

1. Corpino, S.; Caldera, M.; Nichele, F.; Masoero, M.; Viola, N. Thermal design and analysis of a nanosatellite in low earth orbit. Acta Astronaut. 2015, 115, 247-261. [CrossRef]

2. Mehrparvar, A. Cubesat Design Specifications Rev. 13; California Polytechnic State University: San Luis Obispo, CA, USA; Stanford University: Stanford, CA, USA, 2014.

3. Niaki, K.S.; Anvari, A.; Farhani, F. Aluminum and composite materials for satellite structures-A comparison of thermal performance. Mater. Sci. Res. India 2007, 4, 25-34. [CrossRef]

4. Condruz, M.R.; Voicu, L.R.; Puscasu, C.; Vintila, I.S.; Sima, M.; Deaconu, M.; Dragasanu, L. Composite material designs for lightweight space packaging structures. INCAS Bull. 2018, 10, 13-25. [CrossRef]

5. Ampatzoglou, A.; Baltopoulos, A.; Kotzakolios, A.; Kostopoulos, V. Qualification of Composite Structure for Cubesat Picosatellites as a Demonstration for Small Satellite Elements. IJASAR 2014, 1, 1-10. [CrossRef]

6. Shemelya, C.; De la Rosa, A.; Torrado, A.R.; Yu, K.; Domanowski, J.; Bonacuse, P.J.; Martin, R.E.; Juhasz, M.; Hurwitz, F.; Wicker, R.B.; et al. Anisotropy of thermal conductivity in 3D printed polymer matrix composites for space based cube satellites. Addit. Manuf. 2017, 16, 186-196. [CrossRef]

7. Marshall, W.M.; Zemba, M.; Shemelya, C.; Wicker, R.; Espalin, D.; MacDonald, E.; Keif, C.; Kwas, A. Using Additive Manufacturing to Print a CubeSat Propulsion System. In Proceedings of the 51st AIAA/SAE/ASEE Joint Propulsion Conference, Orlando, FL, USA, 27-29 July 2015.

8. Borgeaud, M.; Scheidegger, N.; Noca, M.; Roerhlisberger, G.; Jordan, F.; Choueiri, T.; Steiner, N. SwissCube: The First Entirely-Built Swiss Student Satellite with an Earth Observation Payload. In Small Satellite Missions for Earth Observation; Sandau, R., Roeser, H.P., Valenzuela, A., Eds.; Springer: Berlin, Germany, 2010; pp. 207-213, ISBN 978-3-642-03501-2.

9. Hussain, F.; Hojjati, M.; Okamoto, M.; Gorga, R.E. Review article: Polymer-matrix Nanocomposites, Processing, Manufacturing, and Application: An Overview. J. Compos. Mater. 2006, 40, 1511-1575. [CrossRef]

10. Paul, D.R.; Robeson, L.M. Polymer nanotechnology: Nanocomposites. Polymer 2008, 49, 3187-3204. [CrossRef]

11. Gonzalez-Garcia, P.; Ramirez-Aguilar R.; Torres, M.; Franco-Urquiza, E.A.; May-Crespo, J.; Camacho, N. Mechanical and thermal behavior dependence on graphite and oxidized graphite content in polyester composites. Polymer 2018, 153, 9-16. [CrossRef]

12. Kang, S.J.; Oh, H.U. On-Orbit Thermal Design and Validation of 1 U Standardized CubeSat of STEP Cube Lab. Int. J. Aerosp. Eng. 2016, 2016, 4213189. [CrossRef]

13. Panczak, T.D.; Ring, S.G. RadCAD ${ }^{\circledR}:$ Next Generation Thermal Radiation Analyzer. SAE Int. 1997. [CrossRef]

14. Chandrasekaran, V.; Subramanian, E.R. Transient thermal analysis of a nanosatellite in low earth orbit. In Proceedings of The Eighth International Conference on Engineering Computational Technology; Topping, B.H.V., Ed.; Civil-Comp Press: Stirlingshire, UK, 2012. 
15. Yoo, J.; Jin, H.; Seon, J.; Jeong, Y.H.; Glaser, D.; Lee, D.H.; Lin, R.P. Thermal Analysis of TRIO-CINEMA Mission. J. Astron. Space Sci. 2012, 29, 23-31. [CrossRef]

16. Kandelbauer, A. Cyanate Esters. In Handbook of Thermoset Plastics, 3rd ed.; Dodiuk, H., Goodman, S.H., Eds.; William Andrew Publishing: Boston, MA, USA, 2014; pp. 425-457, doi:10.1016/B978-1-4557-3107-7.00011-7.

17. Toray Advanced Composites. Toray EX-1510 Cyanate Resin, Two Part System Data Sheet. Available online: https:/ / www.toraytac.com/product-explorer/products/ntro/EX-1510 (accessed on 8 August 2019).

18. FAR 25.853-Appendix F Part II. Fire Test to Aircraft Material_Flammability of Seat Cushions; Federal Aviation Administration, Department of Transportation: Washington, DC, USA, 2018.

19. Sika-AXSON Corporation. EPOLAM 2500, Epoxy System FAR 25 Approved. Available online: https:// advanced-resins.sika.com (accessed on 10 September 2018).

20. Nakamura, S.; Fuji, T.; Matsukawa, S.; Katagiri, M.; Fukuyama, H. Specific heat, thermal conductivity, and magnetic susceptibility of cyanate-ester resins-An alternative to commonly used epoxy resins. Cryogenics 2018, 95, 76-81. [CrossRef]

21. Toldy, A.; Szlancsik, A.; Szolnoki, B. Reactive flame retardancy of cyanate ester/epoxy resin blends and their carbon fibre reinforced composites. Polym. Degrad. Stab. 2016, 128, 29-38. [CrossRef]

22. Chen, J.; Liu, B.; Yan, L. Transport of thermal energy in epoxy matrix composites reinforced with a hybrid carbon nanofiller. Results Phys. 2019, 14, 102363. [CrossRef]

23. European Commission Directorate-General for Energy. Horizon 2020, EU Energy Trends to 2030. Climate Action DG and Mobility and Transport DG, 2020 Climate and Energy Package; Publications Office of the European Union: Luxembourg, 2010.

24. Torres, M.; Piedra, S.; Ledesma, S.; Perez, R.; Franco J.A. Thermal and mechanical analysis of a Carbon-Epoxy laminates for CubeSat primary structures. In Proceedings of the 5th International Conference on Mechanics of Composites (MechComp 2019), Lisbon, Portugal, 1-4 July 2019.

25. Patterson, B.A.; Sodano, H.A. Enhanced Interfacial Strength and UV Shielding of Aramid Fiber Composites through ZnO Nanoparticle Sizing. ACS Appl. Mater. Interfaces 2016, 8, 33963-33971. [CrossRef] [PubMed]

26. Salla, J.; Pandey, K.K.; Srinivas, K. Improvement of UV resistance of wood surfaces by using ZnO nanoparticles. Polym. Degrad. Stab. 2012, 97, 592-596. [CrossRef]

27. Camacho, N.; May-Crespo, J.F.; Rojas-Trigos, J.B.; Mondragon-Rodriguez, G.C.; Martinez, K.; Marin, E. Thermal properties and degradation kinetics of epoxy- $\gamma$-alumina and epoxy-zinc oxide composites. Polym. Test. 2019, Submitted.

28. Sanchez-San Juan, S.; Gonzalez-Llorente, J.; Hurtado-Velasco, R. Comparison of the Incident Solar Energy and Battery Storage in a 3U CubeSat Satellite for Different Orientation Scenarios. J. Aerosp. Technol. Manag. 2016, 8, 91-102. [CrossRef]

29. HEXCEL Corporation. HexTow AS4 Carbon fibre Datasheet; Hexcel Corporation: Stamford, CT, USA, 2016.

30. Anderson, B.J.; Justus, C.J.; Batts, G.W. Guidelines for the Selection of Near-Earth Thermal Environment Parameters for Spacecraft Design; NASA/TM-2001-211221; NASA: Huntsville, AL, USA; 2001.

31. Jaques, L. Thermal Design of the OUFTI-1 Nanosatellite. Master's Thesis, University of Liege, Liege, Belgium, 2009.

32. Gilmore, D. Spacecraft Thermal Control Handbook, Volume 1: Fundamental Technologies; Aerospace Press: Reston, VA, USA, 2002.

33. ANSYS Mechanical User's Guide. Available online: https://www.sharcnet.ca/Software/Ansys/18.2.2/enus/help/ai_sinfo/mech_intro.html (accessed on 25 January 2019).

34. Dasgupta, A.; Agarwal, R.K. Orthotropic thermal conductivity of plain-weave fabric composites using a homogenization technique. J. Compos. Mater. 1992, 26, 2736-2758. [CrossRef]

35. Hubbard, J.A.; Brown, A.L.; Dodd, A.B.; Gomez-Vasquez, S.; Ramirez, C.J. Carbon Fiber Composite Characterization in Adverse Thermal Environments; SAND2011-2833; Sandia National Laboratories: Albuquerque, NM, USA, 2011.

(C) 2019 by the authors. Licensee MDPI, Basel, Switzerland. This article is an open access article distributed under the terms and conditions of the Creative Commons Attribution (CC BY) license (http:/ / creativecommons.org/licenses/by/4.0/). 